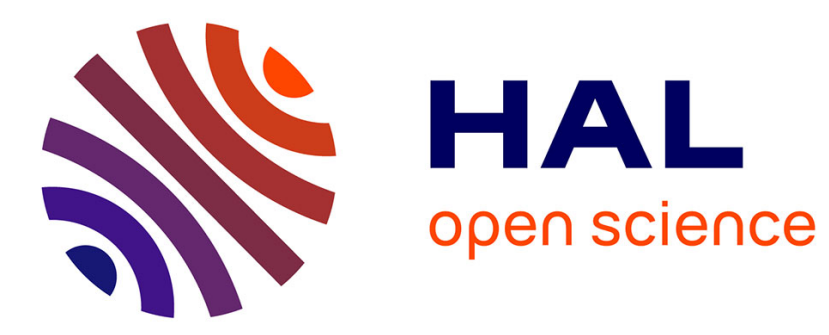

\title{
GARP violation, Economic Environment Distortions and Shadow Prices: Evidence from Household Expenditure Panel Data
}

\author{
Marc-Arthur Diaye, François Gardes, Christophe Starzec
}

\section{To cite this version:}

Marc-Arthur Diaye, François Gardes, Christophe Starzec. GARP violation, Economic Environment Distortions and Shadow Prices: Evidence from Household Expenditure Panel Data. 2009. halshs00376747

\section{HAL Id: halshs-00376747 https://shs.hal.science/halshs-00376747}

Submitted on 20 Apr 2009

HAL is a multi-disciplinary open access archive for the deposit and dissemination of scientific research documents, whether they are published or not. The documents may come from teaching and research institutions in France or abroad, or from public or private research centers.
L'archive ouverte pluridisciplinaire HAL, est destinée au dépôt et à la diffusion de documents scientifiques de niveau recherche, publiés ou non, émanant des établissements d'enseignement et de recherche français ou étrangers, des laboratoires publics ou privés. 


\section{Documents de Travail du Centre d'Economie de la Sorbonne}

$\left[\begin{array}{c}\text { - PANTHÉON - SORBONNE - } 1 \\ \text { NIVERSITÉ PARIS }\end{array}\right.$
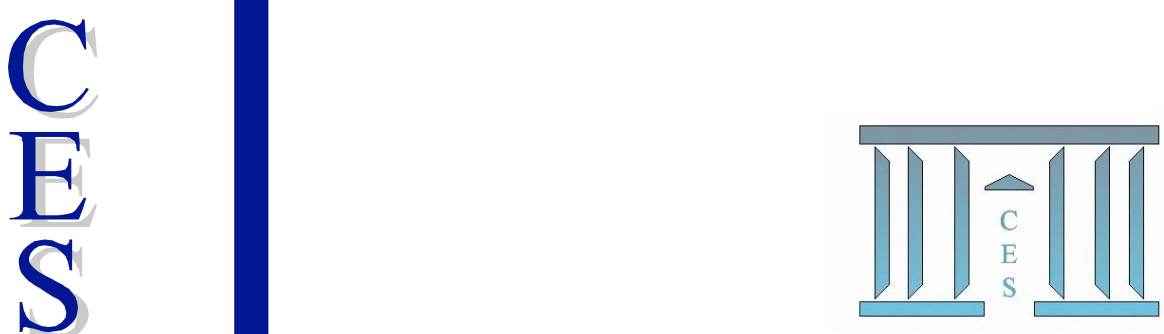

GARP violation, Economic Environment Distortions and

Shadow Prices : Evidence from Household Expenditure Panel Data

Marc-Arthur DIAYE, François GARDES, Christophe STARZEC

2009.20

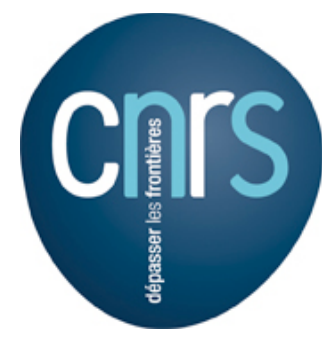

Maison des Sciences Économiques, 106-112 boulevard de L'Hôpital, 75647 Paris Cedex 13 http://ces.univ-paris1.fr/cesdp/CES-docs.htm 


\title{
GARP violation, Economic Environment Distortions and Shadow Prices: Evidence from Household Expenditure Panel Data*
}

\author{
Marc-Arthur DIAYE ${ }^{\dagger}$ François GARDES $\ddagger$ Christophe STARZEC ${ }^{\S}$
}

\footnotetext{
*We would like to thank the Editor and the referees who helped us to substantially improve this paper. We are indebted to Greg Duncan for partly orienting this work, to Joe Altonji for his remarks at an early stage of this research, and to Denys Pommeret. We thank Professor Gorecki (Warsaw University) for allowing us to use the Polish panel data set. Marc-Arthur Diaye would like to acknowledge the grant from CREST during his stay at Northwestern University. Previous versions of this paper have been presented at various seminars (University of Paris 1, University of Paris 12, University of Paris 10, CREST, UQAM) and conferences (the 56th ESEM in Lausanne, the 9th Congress of Panel Data in Geneva, the 17e Journées de Micro-Economie Appliquée at Quebec). This paper was written while François Gardes was researcher at CREST-LSM.

${ }^{\dagger}$ Centre d'Etudes de l'Emploi, University of Evry (EPEE) and TEPP (FR no. 3126, CNRS). marc-arthur.diaye@enpc.fr.

${ }^{\ddagger}$ Paris School of Economics, University of Paris 1 (Centre d’Economie de la Sorbonne). francois.gardes@univ-paris1.fr

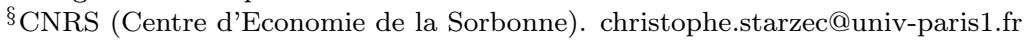




\begin{abstract}
This paper contributes to the discussion of the compatibility of consumers' behavior in "real" life with GARP. Within expenditure panel data we observe a relatively low rate of violation (240 out of 3630 households). We show that these violations do not imply an "irrational" behavior of the agents, but can be attributed to a change in the agents' choice conditions during a period of time, which includes a shift from a centrally planned towards a market oriented economy.
\end{abstract}

Keywords: GARP, Shadow prices.

JEL Classification: C14, D11, D12

Violation de GARP, Distortion de l'environnement économique et Prix virtuels: Analyse à partir de données de panel

\title{
Résumé
}

Cet article discute de la compatibilité du comportement des consommateurs dans la vie réelle avec l'axiome GARP. A partir du panel polonais de 1987 à 1990, nous montrons que seulement 240 des 3630 ménages violent GARP. Ces violations ne semblent néanmoins pas indiquer un comportement irrationnel: elles correspondraient plutôt à des changements dans les conditions de choix des agents dans une période caractérisée par le passage d'une économie de rationnement à une économie de marché.

Mots Clés: GARP, Prix virtuels.

Classification JEL: C14, D11, D12 


\section{Introduction}

Non-parametric tests applied to aggregate time series data confirm, in general, the hypothesis of a representative agent maximizing utility function. Neither VARIAN [1982] analyzing aggregate consumption data, nor SWOFFord and Whitney [1986], who analyzed quarterly data on monetary assets in the USA for the period 1969:11979:4, found a violation ${ }^{1}$ of the GARP axiom (Generalized Axiom of Revealed Preference). Chalfant and Alston [1988], analyzing US meat demand from 1947 to 1983 and Australian quarterly meat demand from 1961:1 to 1984:4, tested the consistency of the data with an axiom called SARP (Strong Axiom of Revealed Preference) which is more restrictive than GARP. They found no violation for the US and only two violations for Australia. The reason for such a result over aggregate time series data is now well-known: when using aggregate data, few or no budget hyperplanes intersect, leading to a trivial respect for GARP.

On the contrary, non-parametric tests performed over micro-economic data do not give a clear cut answer concerning consumers' respect of rationality axioms (GARP, SARP, WARP). For instance, MATTEI [1994], using a monthly Swiss Consumer Panel Data (1975-89) ${ }^{2}$ showed that half of the households, and all households whose choices were recorded during at least 60 months, violated GARP. This issue especially concerns the 19 households whose choices were recorded from 1975 to 1989. SIPPEL [1997, page 1443], over two experimental consumer data sets of 12 and 30 individuals respectively, concluded the following: "We find a considerable number of violations of the revealed preference axioms, which contradicts the neo-classical theory of the consumer maximizing utility subject to budget constraint. We should therefore pay closer attention to the limits of this theory as a description of how people actually behave, i.e. as a positive theory of consumer behavior". The author indeed has found out in his first experiment that 11 individuals (over a total of 12 ) violated SARP and 5 individuals $(41.7 \%)$ violated GARP. He also found out, in his second experiment, that 22 individuals (over a total of 30) violated SARP and 19 violated GARP. MATTEI [2000], over three experimental consumer data sets, reached the same result ${ }^{3}$. However, a

\footnotetext{
${ }^{1}$ However some violations are found over some subsets of the entire data, simply indicating general interaction between monetary assets.

${ }^{2}$ It actually includes several overlapped sets of panel data over the time period since only 19 households remained from 1975 to 1989.

${ }^{3}$ See also Andreoni and Miller [2002] or Harbaugh et al. [2001].
} 
paper ${ }^{4}$ by FÉVRIER and VISSER [2004] over two experimental data sets of respectively 60 and 60 individuals found that "only" 35 (over 120 ) individuals (29\%) violate GARP. Moreover, FAMULARI [1995], using repeated cross-sections of households from the 1982-1985 Consumer Expenditure Survey ${ }^{5}$ divided into mutually exclusive 43 demographic groups according to eight demographic characteristics, found out that 42 groups respected GARP.

In order to explain the purpose of our paper, let us make two remarks:

First, recall that the GARP (or SARP, WARP) test is based on the preference which is revealed by the data sets. Therefore, the GARP test is valid only if this preference revealed by the data sets is the agent's true preference. This implies that sometimes a violation of GARP (or SARP, WARP) simply means that the preference revealed by the data sets (the revealed preference) is not the agent's true preference. For instance, if the agent has changed his preference at least once over the period of investigation, then the revealed preference is not the agent's true preference, and this preference instability may lead to a violation of GARP. Another example would be where the constructed budget domain (constructed from the observed quantity-vectors $x$ and prices $p$ ) is not the agent's true domain: there is a budget set $B^{0}$ over which the agent in fact chooses and which does not belong to the constructed domain. This case can arise if the budget sets are nonlinear in the sense of MATZKIN [1991], or if some of the observed price vectors (the price vectors in the data sets) are not the price vectors actually used by the agent (i.e. the agent uses a complete price which includes an unobservable non-monetary component).

Second, let us recall that the GARP test aims to test the existence of a utility function that rationalizes the data set. From a mathematical standpoint, a utility function is an order homomorphism. Therefore, over a finite set, having an agent's utility represented by a utility function is equivalent to this agent's preference relation being complete and transitive. However, as shown by the literature on the theory of preference relation, the agents' preference relations are not transitive in general. Unfortunately, such an agent with a nontransitive preference relation will violate GARP and SARP, even if

\footnotetext{
${ }^{4}$ The subjects are not, as usual, recruited from the university staff or students, but are randomly selected from the population of Dijon, France.

${ }^{5}$ Annual household expenditures are aggregated in nine categories and prices are differentiated according to the metropolitan area.
} 
his or her choice corresponds to the optimal element with respect to her preference relation.

The main conclusion from our paper is the following: a test of GARP needs to be accompanied by an empirical analysis of the reasons why some individuals violate $G A R P^{6}$. Otherwise, we can conclude that these individuals are "irrational" while they are most emphatically "rational". This dilemma is not trivial, since the standard non-parametric robustness tests (checking for trivial respect of the axioms, Afriat efficiency tests, power...) are not helpful in dealing with this issue. For instance, as argued above, if the observed budget domain, constructed from the observed quantity-vectors $x$ and prices $p$, is not the agent's true domain, then a test of GARP on this domain may lead to a violation of GARP even if the agent is "rational".

We used a panel data of 3630 households (Polish Consumer Panel Data 1987-1990) over a period with very high price variations and smaller, real income variations. Thus, budget hyperplane intersections were likely to occur, and the violation of axioms as well. We tested the axioms (GARP, SARP, and WARP) over a panel data of 3630 households (Polish Consumer Panel Data 1987-1990). We found that 240 households over 3630 formally violated the rationality axioms. It seems, however, according to our various tests and analysis, that even these 240 households are actually utility function maximizers.

Indeed, when we analyze the revealed preference relations of the 240 households who violated GARP, we find that over the 240 revealed preferences, 189 are preorders (complete and transitive), 16 are partial order (reflexive, transitive but non complete), and 35 are acyclic. Since partial orders can be extended into preorders without loss of generality (according to the extension theorem of Szpilrajn), then 205 households who violate GARP are preorder preference maximizers (that is, they maximize a utility function). And this is contradictory, since utility function maximizing implies the fulfillment of GARP. Hence under the assumption that the optimizing principle is fulfilled, it is more likely that the associated constructed budget domain $F$ (constructed from the observed quantityvectors $x$ and prices $p$ ) of the 240 violating households is not true:

${ }^{6}$ Even in the case of experimental data sets (see Diaye and Wong-Urdanivia [2008]). 
the observed revealed preference $R$ is not the true preference of a violating household. And if we suppose that that the households' non-observed true preferences (denoted $R^{\prime}$ ) are preorder preferences, then it must be the case that the price distributions that the households use in order to determine their true non-observed preferences $R^{\prime}$ are necessarily different from the observed monetary price distributions used to determine the revealed preference $R$. We interpret the prices used by the households to determine $R^{\prime}$ as their complete prices; that is $p_{i}^{\prime}=p_{i}+\pi_{i}$; where $p_{i}$ is the observed monetary price and $\pi_{i}$ is an unobserved shadow price corresponding to non-monetary resources and to constraints faced by the households. Hence, the true budget domain is $F^{\prime}$ while the statistician observes $F$. That is, the revealed preference $R$ built from $F$ is an approximation of $R^{\prime}$ built from $F^{\prime}$ : the 240 violating households face a change in their choice conditions ${ }^{7}$ so the displayed revealed preferences $R$ are different from their underlying true preferences $R^{\prime}$.

Our explanation is corroborated by two empirical findings:

First, Polish households seem to have been confronted with drastic subsistence constraints (which can correspond to shadow price effects) during 1987-1990. Indeed, their level of well-being was much affected by inflation and macroeconomic shocks: between 1988 and 1989, the real income per UC for households belonging to the first quartile decreased by $30 \%$ and increased by the same amount for households belonging to the last quartile. An inverse change occurred between 1989 and 1990.

Second, we tested, through an econometric model, the assumption that during this period the 240 violating households faced a change in their shadow prices, through drastic modifications of their non-monetary resources (such as a substitution between the monetary and non-monetary component of price due to the existence of queuing during the pre-transition period) and the appearance of new constraints (such as subsistence constraints). We computed the shadow prices by estimating a Quadratic Demand System separately for the two types of households. And we found out that the change in shadow prices (identified by the endogeneity biases on cross-section estimations) is large for both populations and significantly greater for the violating households during the whole period. Thus the violation of rationality axioms by the 240 households seems to be a "rational" adjustment of their behavior to special choice conditions.

\footnotetext{
${ }^{7}$ We have checked, of course, for other reasons.
} 
This paper includes 6 sections. Section 2 introduces the nonparametric tests. Section 3 is devoted to the Polish Consumer Panel Data (1987-1990). Section 4 deals with the non-parametric tests' results, and in section 5 we estimate a parametric econometric model of complete prices. Section 6 is the conclusion.

\section{The non-parametric tests}

Let $D=\left\{\left(x_{i}, p_{i}\right)\right\}_{i=1}^{N}$ be a data set including prices $p_{i} \in \mathbb{R}_{+}^{n}$ and bundles of goods $x_{i} \in \mathbb{R}_{+}^{n}$ purchased at price $p_{i}$.

In order to define WARP (Weak Axiom of Revealed Preference), GARP (Generalized Axiom of Revealed Preference) and SARP (Strong Axiom of Revealed Preference), we need to recall the definition of the so-called revealed preference $R$ :

$$
\forall x_{i}, x_{j}, \quad x_{i} R x_{j} \text { if } p_{i} x_{j} \leq p_{i} x_{i}
$$

The interpretation of $R$ is the following: A bundle of goods $x_{i}$ is revealed preferred to $x_{j}$, at the price vector $p_{i}$ if $x_{j}$ could have been chosen by the agent while $x_{i}$ is chosen. Indeed, at the price vector $p_{i}, x_{j}$ is less expensive than $x_{i}$, but the latter is the one which is, as observed, chosen by the agent.

Let us also state the definition of the so-called strict revealed preference $R S$ :

$$
\forall x_{i}, x_{j}, \quad x_{i} R S x_{j} \text { if } p_{i} x_{j}<p_{i} x_{i}
$$

Let $R^{*}$ be the transitive closure of $R$, the SARP required $R^{*}$ to be antisymmetric, the WARP (SAMUELSON [1948]) required revealed preference relation $R$ to be antisymmetric while the GARP (VARIAN [1982]) required bilateral asymmetry of $R^{*}$ and $R S: \forall x_{i}, x_{j} \in$ $X, \quad x_{i} R^{*} x_{j} \Rightarrow \operatorname{not}\left(x_{j} R S x_{i}\right)$.

It is obvious that SARP implies GARP and WARP. However, there is no relationship in general ${ }^{8}$ between GARP and WARP.

\footnotetext{
${ }^{8}$ Nevertheless, in two-dimensional Euclidean space, the three axioms are equivalent (SAmuelson [1948], Rose [1958]). Moreover, if we restrict ourselves to the class of univalent choice functions (choice functions $C$ such that $\operatorname{Card} C(S)=1$, whatever $S$ a choice set), then GARP implies WARP.
} 
When a data set $D=\left\{\left(x_{i}, p_{i}\right)\right\}_{i=1}^{N}$ fulfills SARP then there exists a stable local non-satiated complete order preference (transitive, antisymmetric, complete) $Q \subseteq \mathbb{R}_{+}^{n} \times \mathbb{R}_{+}^{n}$ which rationalizes the data set $\forall x \in \mathbb{R}_{+}^{n}$ such that $p_{i} x \leq p_{i} x_{i}$, and we have $x_{i} Q x$. There exists a utility function that rationalizes the data set $D$. There also exists a demand function that rationalizes the data set $D$.

When a data set $D$ fulfills GARP then there exists a stable locally non-satiated preorder (transitive, complete) preference which rationalizes the data. There is a utility function that rationalizes the data set, and there is a demand correspondence that rationalizes the data set.

When the data set fulfills WARP then there exists a stable locally non-satiated complete and antisymmetric preference which rationalizes the data. There is a function that rationalizes the data (but nothing can be said about the nature of this function).

\section{The Data}

Household budget surveys have been realized in Poland for many years. During the analyzed period, the annual total sample size was about 30 thousand households. The data was collected by a rotation method on a quarterly basis. The master sample consists of households and persons living in randomly selected dwellings. The full description of the master sample generating procedure is given by KorDOs and KUBICZEK [1991].

As to the sub-samples, the first pair of sub-samples were surveyed from 1986 to 1989 (survey period being four years) and replaced by new sub-samples in 1990. A second pair of sub-samples of the same size was surveyed from 1987 to 1990.

Over this four-year period, on every annual sub-sample, it is possible to identify households participating in the surveys. The number of checked and tested households is 3736. However, 3630 households remain in the data set after deleting households with missing values. The available information is detailed concerning the cross-sectional surveys: all typical socio-economic characteristics of households and individuals are present, as well as details on income and expenditures. Household expenditures are aggregated into nine categories: Food, Alcohol and Tobacco, Culture, Energy, Clothing, Housing, Medical Care and Hygiene, Transportation and Communication, "Other". 
A large part of this panel (the one containing demographic and income variables) is included in the comparable international database of panels subject to PACO project (Luxembourg) and is publicly available.

Prices and price indices are those reported by the Polish Statistical Office (GUS) for main expenditure items. They are quarterly observed and differentiated by 4 social categories: workers, retired people, farmers, and dual activity persons (farmers and workers). This distinction implicitly covers geographical differentiation: workers and retired live mostly in large and average sized cities, farmers live in the countryside, and dual activity persons live mostly in the countryside and in small towns. The individual price index differences can be interpreted as a consequence of the behavioral specificity determined by the social class, life cycle, and consumption needs. The regional differentiation is less significant in the context of the panel's period that covers the time of administrated prices, which is identical for the whole country (1987-1989). Only coexisting free (or parallel) markets might have created some influence on regional average price differences. These differences are taken into account through social differentiation.

Tables 2.1 and 2.2 in Appendix II provide some descriptive information about the Polish data. The period 1987-1990 covered by the Polish panel is unusual even in Polish economic history. It represents the shift from a centrally planned, rationed economy (1987) to a relatively unconstrained and fully liberal market economy (1990). GDP grew by $4.1 \%$ between 1987 and 1988, but fell by $.2 \%$ between 1988 and 1989 and by $11.6 \%$ between 1989 and 1990. Price increases across these pairs of years were $60.2 \%, 251.1 \%$ and $585.7 \%$, respectively. Thus, the transitory years 1988 and 1989 have produced a period of a very high inflation and a mixture of free-market, shadow, and administrated economy.

\section{The Results of the Non-parametric Tests}

\subsection{Tests}

Over the 3630 households, 3390 respect SARP, and then GARP, and WARP, and 240 violate the axioms SARP, GARP, and WARP. The robustness tests (including the power) are discussed in Appendix I. 
Table 1. Simultaneous tests of SARP, GARP and WARP.

\begin{tabular}{|c|c|c|}
\hline & $\begin{array}{c}\text { Respect of SARP, } \\
\text { GARP and WARP: } \\
\text { Number of violation }=0\end{array}$ & $\begin{array}{c}\text { Non Respect of SARP, } \\
\text { GARP and WARP: } \\
\text { Number of violation } \neq 0\end{array}$ \\
\hline Number of households & 3390 & 240 \\
\hline
\end{tabular}

Concerning the 240 violating households, there are two possibilities. Either the observed revealed preferences (denoted $R$ ) are the households true preferences or they are not their true preferences.

1. If $R$ is the true preference, then the associated observed budget domain $F$ (constructed from the observed quantity-vectors $x$ and prices $p$ ) is also the true budget domain (since $R$ is built from the budget domain $F$ ). Therefore, if $R$ is a preorder (or if $R$ is a partial order ${ }^{9}$ ), then "GARP is violated" implies necessarily that the "optimizing principle is violated". Otherwise, we will have a contradiction between the violation of GARP and the fact that the agent is a utility function's maximizer. If $R$ is only acyclic, then "GARP is violated" either implies that the optimizing principle is violated or implies that the violation of GARP is caused by the non-transitive structure of $R$.

2. If $R$ is not the true preference then the associated observed budget domain $F$ is also not the true budget domain. Hence, the violation of GARP is apparent; it is a violation from the point of view of the statistician who works with $F$.

Let us assume that the optimizing principle is fulfilled by the agent. Under this assumption the associated observed budget domain $F$ can not be the true one, because if $F$ is the true one then $R$ (the revealed preference) is also the true preference. However, when we analyze ${ }^{10}$ the revealed preference relations of the 240 households who violated GARP, we find out that over the 240 revealed preferences, 189 are preorders (complete and transitive), 16 are partial order (reflexive, transitive but non complete), 23 are complete and acyclic, and 12 are reflexive-acyclic but non complete. Since partial orders can be extended into preorders without loss of generality, then $205(85.41 \%)$ households who violated GARP are preorder preference maximizers (that is, they maximize a utility function). And this is contradictory. Hence, under the assumption that the optimizing

\footnotetext{
${ }^{9} \mathrm{~A}$ partial order is a reflexive and transitive binary relation. It can be extended into a preorder according to the extension theorem of Szpilrajn.

${ }^{10}$ Results available upon request from the authors.
} 
principle is fulfilled, it is more likely that the associated (observed) budget domain $F$ of the 240 violating households is not the true: the observed revealed preference $R$ is not the true preference of a violating household. And if we suppose that the households' non-observed true preferences (denoted $R^{\prime}$ ) are preorder preferences, then it must be the case that the price distributions that the households use in order to determine their true non-observed preferences $R^{\prime}$ are necessarily different from the observed monetary price distributions used to determine $R$ (the revealed preference).

We interpret the prices used by an household to determine $R^{\prime}$ as its complete prices, that is $p_{i}^{\prime}=p_{i}+\pi_{i}$; where $p_{i}$ is the observed monetary price and $\pi_{i}$ is an unobserved shadow price corresponding to non-monetary resources and to constraints faced by the household. Hence, the true budget domain is $F^{\prime}$ while the statistician observes $F$. That is, the revealed preference $R$ built from $F$ is an approximation of $R^{\prime}$ built from $F^{\prime}$.

Of course, one may propose many other explanations. For instance:

Explanation (a). The agents are actually households. Therefore, the structure of the revealed preference $R$ may simply express a problem of intra-household allocation.

Explanation (b). The agent has changed his preferences at least once over the period covered by the data set, so the observed revealed preference is a mix of the agent's preferences over the period.

According to Table 2, the distribution of single-households/non single-households is almost identical for the violating households and the non-violating households : $10.4 \%$ of the 240 violating households are single-households and $89.6 \%$ are non single-households; $9.3 \%$ of the 3390 non-violating households are single-households and 90. $7 \%$ are non single-households. Therefore, explanation (a) does not seem to be plausible.

Concerning explanation (b), Table 3 below points out that the year 1989 is involved in most of the violations. Indeed, 1989 is the year where the microeconomic and macroeconomic shocks started in Poland. Moreover, Table 3 seems to suggest that the agents did not face a change of their preferences over the period. If the violating agents did change their preferences over this period, then we should 
expect this change to happen in 1989. However, for 42 households, the pair $\left\{x_{87}, x_{88}\right\}$ is involved in the violations.

Therefore, we favor the explanation stating that the 240 violating households faced a change in their choice conditions, so the displayed revealed preferences $\mathrm{R}$ are different from their underlying true preferences $R^{\prime}$.

Table 2. Single Households/Non Single-Households.

\begin{tabular}{|c|c|c|c|}
\hline Number of & Single-Households & Non Single-Households & Total \\
\hline Violating Households & 25 & 215 & 240 \\
\hline Non-Violating Households & 314 & 3076 & 3390 \\
\hline Total & 339 & 3291 & 3630 \\
\hline
\end{tabular}

Table 3. Pairs involved in Violations.

\begin{tabular}{|c|c|}
\hline & Number of households where $\left\{x_{i}, x_{j}\right\}$ is involved in the violation \\
\hline$\left\{x_{87}, x_{88}\right\}$ & 42 households \\
\hline$\left\{x_{87}, x_{89}\right\}$ & 48 households \\
\hline$\left\{x_{87}, x_{90}\right\}$ & 42 households \\
\hline$\left\{x_{88}, x_{89}\right\}$ & 52 households \\
\hline$\left\{x_{88}, x_{90}\right\}$ & 28 households \\
\hline$\left\{x_{89}, x_{90}\right\}$ & 48 households \\
\hline
\end{tabular}

\subsection{What Economic Explanation for the observed viola- tions?}

\subsubsection{Socio-demographic Characteristics}

A Logit estimation on the violations (Table 2.3 in Appendix II) shows that no classic socio-economic characteristics such as the household's demographic structure and location, the head of household's age, profession or education, and the survey's quarter is significant (at 5\%) in predicting violations ${ }^{11}$. The retired people are the only social category for which a significant increase in violation probability has been observed.

On the other hand, the violations are strongly related to the changes in the household's economic and demographic situation. There is a positive and significant relationship between the probability of axiom violation and the change in real per Unit of Consumption (UC) total expenditure in observed periods between 1987 and 1990. The effect is the strongest and the most significant for

\footnotetext{
${ }^{11}$ This result remains true when restricting the estimation to those households for which the expenditure evaluated at constant price change between two surveys is smaller than $20 \%$ (there remain 3263 households), 15\%, $10 \%$ or $5 \%$.
} 
the last period (1989-90), which coincides with the economic transition shock in Poland. Thus, both factors contribute to the violation process: the way the change in individual well being is taken into account and the impact of structural changes in the whole economy. In the period 1989-1990, a dramatic loss in the purchasing power was accompanied by a shift from a rationing situation on the consumption goods market to an almost equilibrium situation. The other significant effect was the change of family size (especially again in the period 1989-1990), which increased the probability of violation.

\subsubsection{Change in real income and relative prices}

It is possible that the violating and non-violating households do not differ with respect to their average characteristics (as suggested by the logit estimation) but they may behave differently when facing a change in income, relative prices, or other determinants affecting their consumption. To check this, we estimated a Quadratic Almost Ideal Demand System (QAIDS) over the pooled 1987-90 surveys, and used the convergence algorithm proposed by BANKS et al. [1997]:

$$
w_{i h t}=\alpha_{i}+\sum_{j} \gamma_{i j} \ln p_{j t}+\beta_{i} \times \ln \frac{m_{h t}}{a\left(p_{t}\right)}+\left(\frac{\lambda_{i}}{b\left(p_{t}\right)} \times \frac{m_{h t}}{a\left(p_{t}\right)}\right)^{2}+w_{h t} \gamma_{i}+u_{i h t}
$$

with

$$
\operatorname{lna}\left(p_{t}\right)=\alpha_{0}+\sum_{i} \alpha_{i} \ln p_{i t}+0.5 \sum_{i} \sum_{j} \gamma_{i j} \ln p_{i t} \times \ln p_{j t}
$$

and

$$
b\left(p_{t}\right)=\prod_{i} p_{i t}^{\beta_{i}}
$$

where $w_{i h t}$ is the budget share for good $i$, individual $h$, and period $t, p_{i t}$ is the price of good $i$ at period $t$, and $m_{h t}$ is the total expenditure of individual $h$ at period $t$. As the estimated parameters $\alpha_{i}, \beta_{i}, \gamma_{i j}$ enter non-linearly into the equation, the first step consists of estimating the equation (4.1) using a Stone price index $a\left(p_{t}\right)=\prod_{i} p_{i t}^{w_{i}}$ with $w_{i}$ as the average budget share of good $i$ over individuals and periods (that is, imposing $\alpha_{0}=\gamma_{i j}=0$ and $\alpha_{i}=w_{i}$ ). Price elasticities are corrected in order to take into account the difference between the exact price index $a\left(p_{t}\right)$ and the Stone index, as described by PASHARDES [1993]. In the second step, the estimated $\gamma_{i j}$ and $\beta_{i}$ are used to compute $b\left(p_{t}\right)$. At each step, $b\left(p_{t}\right)$ is updated and thus the system is linear in parameters. 
BLUndell and RoBin [1999] have proved the consistency and asymptotic efficiency of this iterative procedure on the maximum likelihood estimate. The estimation is made under additivity and homogeneity restrictions; although homogeneity is not accepted by the data except for clothing (results are similar when homogeneity is not constrained). The cross-section and time-series parameters are estimated by pooling the four 1987-90 surveys with quarter and period dummies to take into account all institutional changes. Crosssection parameters are estimated on the pooled cross-section (third iteration) and the time-series parameters on first differences (third iteration) because the usual between and within transformations do not converge ${ }^{12}$.

We find (Table 2.4 in Appendix II) that income elasticities are significantly greater for the violating households concerning Food at Home, and smaller concerning dynamic expenditures such as Food away from Home. These differences are not significant for crosssection estimations, probably because of the endogeneity bias due to the correlation between the specific effects and the relative income. They are significant for the first difference estimation, which eliminates the endogeneity bias. Thus, either the income distribution and the structure of income changes differ between the two populations, or the food expenditures of the violating households are more sensitive to income changes.

As far as the level of well being is concerned, the violating households have a smaller total expenditure than the non-violating, by $3.7 \%, 3.1 \%$, and $7.4 \%$ in the first three years. Compared to a prediction (for the whole population) by variables such as age, family composition, location, profession, and education, their total expenditures are smaller by $2.5 \%$ to $4.9 \%$ between the first three years, and greater by $3.5 \%$ in $1990^{13}$. Moreover, both income and total expenditures have a smaller increase for the violating households between 1988 and $1989(+23.0 \%$ versus $+32.3 \%$ for disposable income per unit of consumption, $+2.6 \%$ versus $+6.7 \%$ for total expenditures), but decrease much less between 1989 and 1990 (-32.7\% versus $39.0 \%,-21.3 \%$ versus $-34.1 \%)$. Similar variations are observed for low-income families. Thus, the violating households seem to have a smaller level of well being, at least between 1987 and 1989, and seem to be confronted with a different pattern of variation of their well

\footnotetext{
${ }^{12}$ Probably because of the high degree of non-linearity over the integrability terms $b(p)$. Moreover the first difference estimation eliminates more efficiently the endogeneity bias by canceling the specific effects between two periods (recall that the within transformation only cancels the specific effect over the whole period).

${ }^{13}$ Including income to predict total expenditures does not change this pattern.
} 
being during this period. This leads to the question of whether the violating households were specifically confronted, compared to the non-violating households, with some constraints such as subsistence constraints ${ }^{14}$ for the poor in particular.

To estimate the number of poor we first computed the proportion of households having less than the average income minus its standard error. The rich were defined as households having more than the average income plus its standard error. We found that the violating population contains much more "rich" households than the non-violating ( $21.7 \%$ versus $16.3 \%$ in 1987$)$ and a few more "poor" households. Actually, the income distribution of the violating population is more polarized: the income variation coefficient is 12.3 for the violating versus 9.5 for the non-violating.

Second, we defined ${ }^{15}$ the poor using a composite index matching three criteria: their income is smaller than the first quintile of the whole population, their total expenditure is lower (by 25\% in Table 2.5) than the average expenditure for the reference population (defined by age, education, location, socio-professional category, and family structure), and their food budget share is greater than $25 \%$ of the average share for this reference population. We found that the violating population contains more rich households and a bit more poor households than the non-violating. More importantly, one half of the households shift to another poverty class (for instance, from the poor to the quasi-poor) during the whole period, especially between 1988 and 1989, both for the violating and the non-violating groups (see Tables 2.5 and 2.6 in Appendix II). This indicates that these violating households have been confronted with new living conditions and new constraints during the whole period.

Thus, the violation process may be explained as a coherent response to the changing economic position of the household. The next step of our paper is to build an econometric model of subsistence constraints and shadow prices.

\footnotetext{
${ }^{14}$ Despite their smaller level of well-being, their budget share for food consumption is not systematically greater than the budget share of the non-violating households or the budget share predicted by the quadratic demand system.

${ }^{15}$ Four other social classes are defined by the same variables. The results are robust at different definitions of the limits.
} 


\section{$5 \quad$ Subsistence Constraints and Shadow Prices}

\section{$5.1 \quad$ Rationale}

Polish households were confronted with drastic subsistence constraints during 1987-1990. Indeed, their level of well-being was much affected by inflation and macroeconomic shocks: between 1988 and 1989, the real income per UC for households belonging to the first quartile decreased by $30 \%$ and increased by the same amount for households belonging to the last quartile. The inverse change occurred between 1989 and 1990. Such constraints correspond to shadow price effects, which may strongly influence household's consumption and saving decisions. In such a situation, the household's choices can no longer be explained by monetary prices only.

Suppose that a monetary price and two shadow prices corresponding to non-monetary resources and to constraints faced by the households, respectively, are combined together into a complete price. Expressed in logarithm form, we have:

$$
p_{c}=p_{m}+p_{n m}+p_{c s}
$$

where $p_{c}$ denotes the logarithm of the complete price, $p_{m}$ denotes the logarithm of the monetary price, $p_{n m}$ denotes the logarithm of the shadow price corresponding to non-monetary resources, and $p_{c s}$ denotes the logarithm of the shadow price corresponding to constraints faced by the households.

However, it is not possible with our data to distinguish between the two components of the shadow price $\pi=p_{n m}+p_{c s}$.

We want to test the assumption that during this period the 240 violating households faced a change in their shadow prices through drastic modifications of their non-monetary resources (such as a substitution between the monetary and non-monetary component of price due to the existence of queuing during the pre-transition period) and the appearance of new constraints (such as subsistence constraints).

\subsection{Measuring the Shadow Prices}

Suppose that two estimations of the same equation:

$$
x_{i h t}=Z_{h t} \beta_{i}+u_{i h t}
$$


for good $i(i=1$ to $\sharp i)$, household $h$ (with $h=1$ to $H$ ) in period $t \quad(t=1$ to $T)$, with $Z_{h t}=\left(Z_{1 h t}, Z_{2 h t}\right)$, are made on both crosssection and time-series dimensions over the same data-set.

Let us set $u_{i h t}=\alpha_{i h}+\varepsilon_{i h t}$, where $\alpha_{i h}$ is the specific effect which contains all permanent components of the residual for individual $h$ and good $i$. As discussed by MUNDLAK [1978], the cross-section estimators can be biased by a correlation between the explanatory variables $Z_{1 h t}$ and this specific effect. Such a correlation is due to latent permanent variables (such as an event during childhood, characteristics of the parents, or permanent wealth).

This correlation comes from the relationship between such latent variables and some explanatory variables, like $Z_{1 h t}$ in the crosssection. For instance, the relative income position of the household can be related to its wealth or to its inheritance. Those effects are embedded in the specific effect. Thus, the correlation $\delta_{i}$ between the time average of the explanatory variables' vector, $Z_{1 h t}=\left(z_{1 h t}^{k}\right)_{k=1}^{K 1}$, transformed by the Between matrix, $B Z_{1 h t}=\left(\frac{1}{T} \times \sum_{t} z_{1 h t}^{k}\right)_{k=1}^{K 1}$ and the specific effect $\alpha_{i h}, \alpha_{i h}=B Z_{1 h t} \delta_{i}+\eta_{i h}$, will add to the parameter $\beta_{i}$ of these variables in the time average estimation $B x_{i h t}=$ $B Z_{1 h t}\left(\beta_{i}+\delta_{i}\right)+\eta_{i h}+B \varepsilon_{i h t}$, so that the between estimators are biased. Thus, the difference between the cross-section and the timeseries estimators equals $\delta_{i}$.

Let us now assume that the shadow price $\pi_{i h t}$ of good $i$ for household $h$ in period $t$ depends on a vector of (endogeneous) characteristics $Z_{1 h t}$, and on a vector of (exogeneous) characteristics $Z_{2 h t}$, that is:

$$
\pi_{i h t}=f_{i}\left(Z_{1 h t}, Z_{2 h t}\right)
$$

Let us also assume that the consumption function for good $i$ is:

$$
x_{i h t}=g_{i}\left(p_{h t}, Z_{1 h t}, Z_{2 h t}, S_{h t}\right)
$$

with $p_{h t}$ as the vector of prices, $p_{j h t}$ containing (if this vector exists) a shadow, unknown component $\pi_{j h t}$, and $S_{h t}$ the vector of all other determinants.

From the shadow price function $Z_{i h t}=f_{i}\left(Z_{1 h t}, Z_{2 h t}\right)=Z_{1 h t} \theta_{1}+$ $Z_{2 h t} \theta_{2}+\lambda_{i h}+\mu_{i h t}$, we define a vector of endogeneous variables $Z_{1 h t}$ as a vector of all variables correlated with the specific effect $\lambda_{i h}$. For instance, the relative income position of the household, supposed to be invariant, can determine its location, which is correlated with 
purchase constraints. Thus, the household relative income may be related to permanent components of the shadow prices corresponding to these constraints. The vector of exogeneous variables $Z_{2 h t}$ is therefore a determinant of the shadow price, which is not correlated with $\lambda_{i h}$.

The shadow prices are unknown and do not appear in the consumption function (5.3). However, their influence is included in the residual, so that the specific effect $\alpha_{i h}$ of the consumption function (with a residual $u_{i h t}=\alpha_{i h}+\varepsilon_{i h t}$ ) contains $\lambda_{i h}$. Therefore, the coefficients of the endogeneous variables $Z_{1 h t}$ in the consumption function are subject to an endogeneity bias, which makes their cross-section, and time-series estimators, different, while the exogeneous variables have coefficients which do not differ between these two dimensions. Thus, the part of the shadow prices, which is explained by $Z_{1 h t}$, can be identified by the endogeneity bias in the consumption function, observed as the difference between the cross-section and time-series estimations of the coefficients of $Z_{1 h t}$.

Indeed, the marginal propensity to consume with respect to $Z_{1 h t}$, when considering the effect of the shadow prices $\pi_{j h t}$ on consumption, can be written:

$$
\frac{d x_{i h t}}{d Z_{1 h t}}=\frac{d g_{i}}{d Z_{1 h t}}+\sum_{j} \frac{d g_{i}}{d \pi_{j h t}} \times \frac{d \pi_{j h t}}{d Z_{1 h t}}
$$

The second term differs between cross-section and time-series variations because of the endogeneity bias in the shadow price inclination with respect to $Z_{1 h t}$. So, comparing two different households surveyed in the same period, this bias adds to the direct consumption propensity with respect to $Z_{1 h t}$, as estimated on timeseries. This parameter will therefore differ between cross-section and time-series estimations. For instance, the influence of the head of household's age cohort or income may differ on cross-sections and time-series if the shadow prices depend on cohort effects or relative income position (the same can occur for monetary prices). Hence the comparison of estimations computed on cross-sections and timeseries reveals the difference of the shadow price system between two households.

The component $\sum_{j} \frac{d g_{i}}{d \pi_{j h t}} \times \frac{d \pi_{j h t}}{d Z_{1 h t}}$ of the marginal propensity of endogenous variables can be used to identify the shadow prices' variation over $Z_{1 h t}, \frac{d \pi_{j h t}}{d Z_{1 h t}}$, since it can be computed by resolving a sys- 
tem of $n$ linear equations after having estimated the price marginal propensities $\frac{d g_{i}}{d \pi_{j}}=\gamma_{i j}$.

We consider here only the direct effect through the price of good $i$ : $\gamma_{i i} \times \frac{d \pi_{i}}{d Z_{1}}$ of the variables $Z_{1 h t}$, so that:

$$
\frac{d \pi_{i}}{d Z_{1}}=\frac{\beta_{i}^{(\text {c.s. })}-\beta_{i}^{(t . s .)}}{\gamma_{i i}}
$$

Note that the price effect $\gamma_{i i}$ is supposed to be the same for monetary and shadow prices. Thus, the change between two periods in the shadow price can be written:

$$
d l n \pi_{i h t}=\sum_{k}\left(\frac{d \pi_{i}}{d z_{1}^{k}}\right) \cdot d z_{1 h t}^{k}
$$

Under the homogeneity assumption (of degree $m$ ) of the shadow prices over variables $Z_{1 h t}$, the value of the shadow prices can be computed as $\ln \pi_{i h t}=m \times \sum_{k}\left(\frac{d \pi_{i}}{d z_{1}^{k}}\right) \cdot d z_{1 h t}^{k}$. However, this homogeneity assumption is quite strong, and we would prefer to compute only the change in the shadow logarithmic prices. Let us call $I_{a}$ and $I_{q}$ the absolute and quadratic average indices for the absolute and quadratic changes in the shadow logarithmic price:

$$
I_{a}\left(\pi^{v}\right)=\frac{1}{H} \times \sum_{h}\left[\frac{1}{T-1} \sum_{t} \sum_{i} w_{i} \cdot\left|d \ln \pi_{i h t}\right|\right]
$$

and

$$
I_{q}\left(\pi^{v}\right)=\sqrt{\frac{1}{H} \times \sum_{h}\left[\frac{1}{T-1} \sum_{t} \sum_{i} w_{i} \cdot\left(d \ln \pi_{i h t}\right)^{2}\right]}
$$

\subsection{Results}

We compute the shadow prices by estimating a Quadratic Demand System separately for the two types of households. However, since the non-violating population is much more numerous, it is not easy to compare the endogeneity biases between the two populations. Moreover, the estimation is less significant for the violating households (see Appendix IV for details). Thus, our preferred estimation was performed on the whole population with a dummy variable indicating the violating households only for the logarithmic income 
and squared logarithmic income variables, which differ significantly (see section 4.2 and Table 2.4 in Appendix II). Therefore the variations of the shadow prices indicate the changes in the conditions of choice for the two populations, weighted by the differences between the same cross-section and the time-series estimators (except for income).

The estimations are performed through cross-section (either pooling the four years in the tables in Appendix III, or averaging them into between data in Table 4) and time-series (either on the first differences between two years in Appendix III, or using the within operator in Table 4). To compute the shadow prices, we compare the cross-section and time-series estimators. For this purpose, we can either equalize the consumptions or their budget shares. The results are similar (see the discussion in Appendix IV and the results in table 3.1, Appendix III). The price elasticities differ in various estimations. The shadow prices strongly depend on the price marginal propensity to consume of the good $i$ (measured by the price coefficient $\gamma_{i i}$ used in formula (5.5)). We calibrate it under the Frisch constraint between income and price elasticities:

$$
E_{i}^{p}=-\varpi \cdot E_{i}^{y} \Rightarrow \gamma_{i i}=(1-\varpi) \cdot w_{i}-\varpi \cdot \beta_{i}
$$

where $E_{i}^{p}$ and $E_{i}^{y}$ are respectively the direct price-elasticity and the income-elasticity for good $i, \varpi$ is the Frisch income flexibility (calibrated as 0.5 as recommended by Selvanathan [1993, Chapter 6]), and $\beta_{i}$ is the estimated coefficient of log-income in an AI Demand System estimation. Table 4 below and Tables 5.1 and 5.2 in Appendix III present an average of the shadow price absolute or quadratic differences between two periods for the violating and non-violating populations. 
Table 4. Index of Quadratic Changes of the Logarithmic Shadow Prices.

\begin{tabular}{|l|c|c|c|c|c|c|c|c|c|}
\hline & \multicolumn{2}{|c|}{$\begin{array}{c}\text { All Expenditures } \\
I_{q}\left(\pi^{v}\right)\end{array}$} & \multicolumn{2}{c|}{$\begin{array}{c}\text { Food at Home } \\
\left(d \ln \pi_{i h t}\right)^{2}\end{array}$} & \multicolumn{2}{c|}{$\begin{array}{c}\text { Housing } \\
\left(d \ln \pi_{i h t}\right)^{2}\end{array}$} & \multicolumn{2}{c|}{$\begin{array}{c}\text { Clothing } \\
\left(d l n \pi_{i h t}\right)^{2}\end{array}$} \\
\cline { 2 - 9 } Period & $\mathrm{NV}$ & $\mathrm{V}$ & $\mathrm{NV}$ & $\mathrm{V}$ & $\mathrm{NV}$ & $\mathrm{V}$ & $\mathrm{NV}$ & $\mathrm{V}$ \\
& & & & & & & & \\
\hline $1987-88$ & 1.29 & 1.498 & 0.078 & 0.109 & 0.07 & 0.086 & 0.031 & 0.022 \\
& $(.01)$ & $(.021)$ & $(.005)$ & $(.013)$ & $(.003)$ & $(.006)$ & $(.001)$ & $(.001)$ \\
\hline $1988-89$ & 1.5 & 1.665 & 0.098 & 0.137 & 0.08 & 0.119 & 0.037 & 0.025 \\
& $(.006)$ & $(.014)$ & $(.007)$ & $(.017)$ & $(.003)$ & $(.009)$ & $(.001)$ & $(.001)$ \\
\hline $1989-90$ & 1.835 & 2.039 & 0.159 & 0.204 & 0.134 & 0.172 & 0.063 & 0.039 \\
& $(.005)$ & $(.011)$ & $(.015)$ & $(.031)$ & $(.007)$ & $(.016)$ & $(.002)$ & $(.002)$ \\
\hline
\end{tabular}

Legend.

$\mathrm{NV}=$ Non-violating households, $\mathrm{V}=$ Violating households

Estimation of the Demand System.

Estimation of a QAIDS under additivity and homogeneity constraints, on Between and Within Transformations for 1987-1990. See Table 2.4 in Appendix II for the specification on instrumented total expenditures.

Computation of the shadow prices.

$d l n \pi_{i h t}=\sum_{i}\left(\frac{d \pi_{i h t}}{d Z_{1 h t}}\right) \cdot d Z_{1 h t}$ with $\frac{d \pi_{i}}{d Z_{1}}=\frac{\beta_{i}^{(c . s .)}-\beta_{i}^{(t . s .)}}{\gamma_{i i}}$.

Only changes $d Z_{1 h}$ of log-income and its square, logarithmic age of the head of household and the proportion of children in the family are taken into account ${ }^{16}$. The shadow price is computed equalizing the budget share (Index TP2 defined in Table 3.1 of Appendix III).

$\underline{\text { Quadratic Index. }}^{17} I_{q}\left(\pi^{v}\right)=\sqrt{\frac{1}{H} \times \sum_{h}\left[\frac{1}{T-1} \sum_{t} \sum_{i} w_{i} \cdot\left(\operatorname{lln} \pi_{i h t}\right)^{2}\right]}$

Computation of the variances. See Appendix V

Three main conclusions:

1. The variations of shadow prices are significantly different from zero $^{18}$ for almost all groups of commodities and for the general indexes $I_{a}\left(\pi^{v}\right)$ and $I_{q}\left(\pi^{v}\right)$. So, these shadow prices may distort the optimal consumption choices of the household.

2. The change in the shadow prices increases significantly during the period. Moreover this increase is particularly large between 1989 and 1990, when inflation, households' income, and economic institutions were experiencing a dramatic change.

\footnotetext{
${ }^{16}$ When adding the logarithmic relative prices to endogeneous variables $Z_{1 h t}$ supposed to contain these four determinants, one must use price parameters which depend, for crosssections on quarter price changes and differences between social categories, and for time-series, on annual price changes. The differences between the four social categories are known only for one period, so that the cross-section and time-series estimators of the price parameters may be similar. The difference between cross-section and times-series estimators is probably due to random factors. Thus, it seems better to take only the four determinants into account.

${ }^{17} \mathrm{An}$ index of absolute variations leads to similar results. Estimations on pooled crosssections and first differences under different hypotheses upon the price coefficient used to compute the shadow prices and the differentiation of the two populations in the estimation also give similar results (see Table 3.1 and Table 5.2 in Appendix III).

${ }^{18}$ Normality being assumed for index $I_{q}$. The distribution of $I_{q}$ was indeed explored by a Monte Carlo Simulation (see Appendix V).
} 
3. The change in shadow prices for all commodities is greater among the violating households, by $4 \%$ to $11 \%$, for the quadratic distance in ${ }^{19}$ Table 4 . The same generally applies for Food at Home, Housing and Clothing expenditures (which sum up to $74 \%$ of all expenditures). Thus, it seems that, between 1987 and 1990, the violating households are confronted with significantly greater changes in their environment than the nonviolating ones.

Finally, according to our parametric tests, the change in shadow prices (identified by the endogeneity biases in cross-section models) is large for both populations and significantly greater for the violating households during the whole period. Thus, as suggested by our non-parametric tests, violation of rationality axioms by the 240 households seems to be a "rational" adjustment of their behavior to special choice conditions.

\section{Conclusion}

The purpose of this paper was to contribute to the current discussion on the compatibility of consumers' behavior in "real" life with the choice consistency axioms. Using expenditure panel data we observed a relatively low rate of GARP, SARP, WARP violation (240 out of 3630 households). Using a shadow prices concept, we showed that the observed violations can be explained by the households' unobserved specific choice conditions, such as economic environment distortions, constraints, or opportunities. That is, the observed violations are not really contradictory with rational behavior axioms.

The data covered a period of very high price variations and smaller real income changes. Budget intersections were therefore more likely to occur, as were the violations of the axioms. Prices were quarterly observed and differentiated by socio-professional category allowing a good computation of quantities. However, while the relative Bronars method 2 power and the Afriat Power Index are satisfying ( $155.5 \%$ and 1.01 respectively), the Bronars method 2 power is very low $(17 \%)$.

\footnotetext{
${ }^{19}$ The change is still greater for different specifications of the consumption function and of the calibration of the price coefficient used to compute the shadow prices (see Appendix IV).
} 


\section{References}

Andreoni J. and Harbaugh W.T. (2006). - "Power Indices for Revealed Preference Tests", mimeo, University of California, San Diego, March 8, 31 pages.

Andreoni J. and Miller J. (2002). - "Giving According to GARP: An Experimental Test of the Consistency of Preferences for Altruism", Econometrica, 70, p.737-753.

Afriat S.N. (1967). - "The Construction of Utility from Expenditure Data", International Economic Review, 8 p. 67-77.

Aizcorbe A.M. (1991). - "A Lower Bound for the Power of Non-parametric Tests", Journal of Business and Economic Statistics, 9, p. 463-467.

Arrow K.J. (1959). - Rational Choice Functions and Orderings", Economica, 26, p. $121-127$.

Baltagi B.H. (1995). - "Econometric Analysis of Panel Data", Chichester, England: John Wiley and Sons.

Banks J., Blundell R. and Lewbel A. (1997). - "Quadratic Engel Curves and Consumer demand", Review of Economic Studies, 89, p. 527-539.

Becker G.S. (1962). - "Irrational Behavior and Economic Theory", Journal of Political Economy, 70, p. 1-13.

Blundell R. and Robin J-M. (1999). - "An Iterated Least Squares Estimator for Conditionally Linear Equations Models", Journal of Applied Econometrics, 14, p. 209-232.

Bronars S.G. (1987). - "The Power of Nonparametric Tests of Preference Maximization", Econometrica, 55, p. 693-698.

Diaye M-A. and Wong-Urdanivia M. (2008). "Violation of transitivity axiom may explain why in empirical studies, a significant number of subjects violates GARP", mimeo, April 25, Centre d'Economie de la Sorbonne, 30 pages.

FAmulari M. (1995). - "A Household-based, Nonparametric Test of Demand Theory", The Review of Economics and Statistics, 77, p. 372-382.

Fevrier Ph. and Visser M. (2004). - "A Study of Consumer Behavior Using Laboratory Data", Experimental Economics, 7, p. 93-114. 
Gross J. (1990). - "On Expenditure Indices in Revealed Preference Tests", Journal of Political Economy, 99, p. 416-419.

Harbaugh W.T., Krause K. and Berry T. (2001). - "GARP for Kids: On the Development of Rational Choice Behavior", American Economic Review, 91; p. 1539-1545.

Kordos J. and KubiczeK A. (1991). - "Methodological Problems in the Household Budget Surveys in Poland", GUS, Warsaw.

Mattei A. (2000). - "Full-scale Real Tests of Consumer Behavior using Experimental Data", Journal of Economic Behavior and Organization, 43, p. $487-497$.

Matzkin R. (1991). - "Axioms of Revealed Preference for Nonlinear Choice Sets", Econometrica, 59, p. 1779-1786.

MundlaK Y. (1978). - "On the Pooling of Time Series and Cross Section Data", Econometrica, 46, p. 483-509.

Pashardes P. (1993). - "Bias in Estimation of the Almost Ideal Demand System with the Stone Index Approximation", Economic Journal, 103, p. 908-916.

Richter K. (1971). - "Rational Choice": in J.S. Chipman, L. Hurwicz, K. Richter and H. Sonnenschein, Eds., Preference, Utility and Demand (Harcourt Brace Jovanovich, New York).

Rose H. (1958). - "Consistency of Preference: The Two-Commodity Case", Review of Economic Studies, 35, p. 124-125.

Samuelson P.A. (1948). - "Consumption Theory in Terms of Revealed Preference", Economica, N.S. 15, p. 243-253.

Selvanathan S. (1993). - "A System-Wide Analysis of International Consumption Patterns", Kluwer Academic Publishers.

Sippel R. (1997). - "An Experiment on the Pure Theory of Consumer's Behaviour", Economic Journal, 107, p. 1431-1444.

VARian H.R. (1982). - "The Nonparametric Approach to Demand Analysis", Econometrica, 50, p.945-973.

VARIAN H.R. (1985). - "Nonparametric Analysis of Optimising with Measurement Error", Journal of Econometrics, 30, p. 445-458.

VARIAn H.R. (1990). - "Goodness-of-fit in Optimizing Models", Journal of Econometrics, 46, p. 125-140. 


\section{A Appendix I: Robustness of the non-parametric tests}

\section{A.1 Method.}

Since the tests are non-parametric, we need to be very careful about their robustness.

First, we need to take into account the "trivial respect" and "trivial violation" of the axioms.

A trivial respect of the axioms arises when, given $\left(x_{i}, x_{j}\right)$, the total expenditure of $x_{i}$ evaluated at a reference price $p_{0}$ is sharply "greater" than the one of $x_{j}$ evaluated at the same reference price. Indeed, in such a case we have $p_{i} x_{i}>p_{i} x_{j}$ and $p_{j} x_{i}>p_{j} x_{j}$. FAMUlari [1995] has developed the following method: She chooses a reference price $p_{0}$ and evaluates all the consumption vectors at this price. The total expenditure of a vector $x_{i}$, evaluated at this constant price $p_{0}$, will be denoted $M_{i}=p_{0} . x_{i}$. If a bundle $x_{i}$ is much more expensive (according to $M_{i}$ ) than a bundle $x_{j}$, it will probably be preferred. Therefore, taking into account the comparison of these two bundles will arbitrary increase the number of couples consistent with GARP. According to Famulari, $\left(x_{i}, x_{j}\right)$ respects GARP if the following index $\frac{2 \times\left(M_{i}-M_{j}\right)}{\left(M_{i}+M_{j}\right)}$ is less than a threshold $K$ arbitrary defined by the experimenter. She takes four different levels for $K: 5 \%, 10 \%$, $15 \%$ and $20 \%$. The interpretation is the following, if $K=k_{0} \%$, it means that we will take into account only the $\left(x_{i}, x_{j}\right)$ such that total expenditures of $x_{i}$ and $x_{j}$ evaluated at constant price $p_{0}$ are different by less than $k_{0} \%$.

$\left(x_{i}, x_{j}\right)$ trivially violates the axioms if the total expenditures of $x_{i}$ and $x_{j}$ evaluated at the available price $p_{i}$ are closed. In such a case, the bundles $x_{i}$ and $x_{j}$ could be considered, by the agent, as identical in such a way that we have $p_{i} x_{i} \geq p_{i} x_{j}$ and $p_{j} x_{j}>p_{j} x_{i}$. In order to take into account possible trivial violations, we follow AFRIAT [1967], who suggests to use the binary relations $R_{e}$ and $R S_{e}$ :

$$
\begin{aligned}
& \forall x_{i}, x_{j}, \quad x_{i} R_{e} x_{j} \Leftrightarrow p_{i} x_{j} \leq e \times p_{i} x_{i} \\
& \forall x_{i}, x_{j}, \quad x_{i} R S_{e} x_{j} \Leftrightarrow p_{i} x_{j}<e \times p_{i} x_{i}
\end{aligned}
$$

where $e \in[0,1]$ is known as the Afriat Efficiency Index (VARIAN [1990]).

Second, we need to evaluate the power of the tests. From a statistical viewpoint the power of a test between two hypotheses is the probability of rejecting the null hypothesis while the alternative hypothesis is true. In our case, the former is that the consumer behavior satisfies the axiom we tested, and the latter that it does not. Unfortunately, because the non-parametric tests of WARP, GARP, and SARP are non-probabilistic, their power is unknown. However, there is a consensus in the literature consisting in computing an approximate power of the nonparametric test. Several methods to approximate the power on non-parametric tests have been developed (see ANDREONI and HARBAUGH [2006] for a review of the existing methods), but the most popular is the one by BRONARs [1987]. Bronars computes the approximate power of the test by 
taking as an alternative hypothesis the BECKER's [1962] notion that the choices of the individuals are made at random (more precisely, choices are probabilistic and are uniformly distributed on the budget set). In this paper, we computed the so-called Bronars Method 2 which draws a number of random budget shares in which the expected share is $1 / n$, where $n$ is the number of goods. The absolute Bronars power index is defined as the average percentage of SARP, GARP, or WARP violating individuals over the $K$ fictive random consumption data exhausting the budget set. The Relative Bronars Power Index is defined as the relative increase of the number of SARP, GARP, or WARP violating individuals when testing the axioms over the initial data sets and over the random consumption data $\operatorname{sets}^{20}$.

We have performed another power test called, by ANDREONI and HARBAUGH [2006], the Afriat Power Index (API). The API is defined as the smallest value of $g$ such that that there is at least one violation of $H-G A R P(g)$. The $H-$ $G A R P(g)$ axiom is defined as follows: if $x_{i} T R_{g} x_{j}$, then $g \times x_{j} p_{j} \leq x_{i} p_{j}$, where $T R_{g}$ is the transitive closure of the binary relation $R_{g}$ defined by $x_{i} R_{g} x_{j} \Longleftrightarrow$ $g \times x_{i} p_{i} \geq x_{j} p_{i}, g \geq 1$. According to AndREOnI and HARBAugh [2006, page $10]$, an API $\leq 1.05$ is "an acceptably powerful test of GARP".

\section{A.2 Results.}

\section{A.2.1 Absolute and Relative Bronars Powers.}

Let us now introduce the results concerning the absolute and relative Bronars powers for 10 random samples (we have also calculated the power over 1000 random samples and we found almost the same average number of violating households as in the case of 10 random samples).

The absolute Bronars method 2 power index (i.e. the percentage of violating households in the random samples) is about $17 \%$. This figure is clearly low. However, the relative Bronars power index (i.e. the relative increase of the number of violating households from the initial data set to the random one) is about $155.5 \%$ : 240 violating households on the initial data set and 613.3 violating households on average on the 10 random samples (see table 1.1 and table 1.2 below).

Table 1.1. Simultaneous tests of SARP over a 10 random samples with respect to Becker's definition (standard-error in brackets)

\begin{tabular}{|c|c|}
\hline & Non-Respect of SARP \\
\hline Number of households (means) & 613.3 \\
& $(20.14)$ \\
\hline
\end{tabular}

\footnotetext{
${ }^{20}$ In order to understand the relative Bronars power index, suppose that when testing GARP over a given data set, the absolute Bronars power index is $99 \%$. What can we conclude if, at the same time, the percentage of GARP violating individuals on this data set is $98 \%$ ? Let us compare this example with the following one where, when testing GARP over a data set, the absolute Bronars power index is $30 \%$, but the percentage of GARP-violating individuals on this data set is $1 \%$. Since the relative increase of GARP-violating individuals is greater in the second example than in the first one, we will say that the relative Bronars power index (that is the relative increase of GARP-violating individuals from the initial data sets to the random consumption data sets) is bigger in the second example than in the first one.
} 
Table 1.2. Afriat Efficiency Tests over the households violating SARP over the 10 random samples.

\begin{tabular}{|c|c|c|c|c|c|c|c|c|c|c|}
\hline & Sample I & II & III & IV & V & VI & VII & VIII & IX & X \\
\hline$e=1$ & 590 & 611 & 617 & 590 & 615 & 648 & 643 & 612 & 615 & 592 \\
\hline$e=0.99$ & 420 & 457 & 440 & 428 & 453 & 472 & 464 & 431 & 462 & 439 \\
\hline$e=0.98$ & 318 & 335 & 306 & 305 & 325 & 336 & 341 & 311 & 322 & 308 \\
\hline$e=0.94$ & 70 & 87 & 83 & 89 & 102 & 95 & 100 & 84 & 88 & 73 \\
\hline$e=0.90$ & 16 & 15 & 22 & 20 & 22 & 21 & 23 & 13 & 19 & 15 \\
\hline$e=0.87$ & 5 & 6 & 4 & 7 & 6 & 4 & 3 & 4 & 1 & 4 \\
\hline$e=0.86$ & 4 & 3 & 2 & 5 & 4 & 1 & 2 & 3 & 1 & 2 \\
\hline$e=0.85$ & 2 & 2 & 1 & 3 & 2 & 1 & 2 & 1 & 0 & 0 \\
\hline$e=0.84$ & 1 & 1 & 0 & 0 & 1 & 0 & 0 & 1 & 0 & 0 \\
\hline$e=0.83$ & 1 & 0 & 0 & 0 & 1 & 0 & 0 & 0 & 0 & 0 \\
\hline$e=0.82$ & 1 & 0 & 0 & 0 & 0 & 0 & 0 & 0 & 0 & 0 \\
\hline$e=0.81$ & 0 & 0 & 0 & 0 & 0 & 0 & 0 & 0 & 0 & 0 \\
\hline
\end{tabular}

\section{A.2.2 Afriat Power Index}

We discover over our data sets an API of 1.01. Let us remind that, according to ANDREONI and Harbaugh [2006, page 10], an API $\leq 1.05$ is "an acceptably powerful test of GARP".

\section{A.2.3 Famulari Robustness Test}

Let us now discuss the robustness concerning the 3390 households, with respect to the axioms. $\left(x_{i}, x_{j}\right)$ trivially respects the axioms when the total expenditure of $x_{i}$ evaluated at a constant price is sharply "greater" than the one of $x_{j}$ evaluated at the same constant price. When taking into account only the $\left(x_{i}, x_{j}\right)$, for which total expenditures of $x_{i}$ and $x_{j}$ evaluated at a constant price are different by less than $K=20 \%, 94.2 \%$ of the initial 3390 households remain consistent. For $K=15 \%, 10 \%$, and $5 \%$, the figures are $83.5 \%, 63.4 \%$, and $33.5 \%$ respectively. The results concerning the households fulfilling the axioms look robust since even at $K=5 \%$ a large proportion of households are still consistent with the axioms (see Table 1.3 below and Part A.1. of this appendix for the definition of $K$ ). Moreover, a logistic regression (see Table 2.3 in Appendix II) shows that the larger the variation in absolute value of real expenditure per UC, the greater the probability of violating the axioms. Thus, the increase of real expenditure is ceteris paribus, and not a cause of respecting the axioms.

Table 1.3. Simultaneous tests of SARP, GARP, and WARP keeping in the revealed preference relation $\mathrm{R}$ only those $\left(x_{i}, x_{j}\right)$ for which the total expenditures on $x_{i}$ and on $x_{j}$, calculated at a reference price, are different by less than $K \%$.

\begin{tabular}{|c|c|}
\hline & Respect of SARP, GARP and WARP \\
\hline$K=20 \%$ & 3194 households \\
\hline$K=15 \%$ & 2832 households \\
\hline$K=10 \%$ & 2149 households \\
\hline$K=5 \%$ & 1139 households \\
\hline
\end{tabular}

\section{A.2.4 Afriat Efficiency Test}

Let us finally discuss the robustness of the 240 households, which violate the axioms. Table 1.4 below gives the results of the Afriat Efficiency test (see 
Part A.1. of this Appendix for the definition). At $e=0.99,54.6 \%$ of the 240 households still violate the axioms but at $e=0.87$, none of them violate the axioms. However, at $e=0.87$, almost all of the 3630 fictive agents we have built also fulfill the axioms (see table 1.2 above).

Table 1.4. Afriat Efficiency Tests over the 240 households violating SARP, GARP, and WARP.

\begin{tabular}{|l|c|}
\hline & Non Respect of SARP, GARP, and WARP \\
\hline$e=1.00$ & 240 households \\
\hline$e=0.99$ & 131 households \\
\hline$e=0.98$ & 84 households \\
\hline$e=0.97$ & 48 households \\
\hline$e=0.96$ & 30 households \\
\hline$e=0.95$ & 18 households \\
\hline$e=0.94$ & 12 households \\
\hline$e=0.93$ & 8 households \\
\hline$e=0.92$ & 6 households \\
\hline$e=0.91$ & 3 households \\
\hline$e=0.90$ & 2 households \\
\hline$e=0.89$ & 1 households \\
\hline$e=0.88$ & 1 households \\
\hline$e=0.87$ & 0 households \\
\hline
\end{tabular}




\section{B Appendix II}

Table 2.1. Means and standard deviations of variables used in the Polish panel analyses.

\begin{tabular}{|c|c|c|c|c|}
\hline & 1987 & 1988 & 1989 & 1990 \\
\hline Budget share for food & $\begin{array}{c}0.480 \\
(.14)\end{array}$ & $\begin{array}{c}0.461 \\
(.15)\end{array}$ & $\begin{array}{c}0.469 \\
(.18)\end{array}$ & $\begin{array}{c}0.540 \\
(.15)\end{array}$ \\
\hline Real total per cu expenditure index & 100 & 105.7 & 118.6 & 79.9 \\
(1987=100) & & & & \\
\hline Relative food price index & 0.961 & 0.902 & 0.992 & 1.145 \\
(pfood/ptotal) & $(.013)$ & $(.06)$ & $(.19)$ & $(.03)$ \\
\hline Ln household total expenditure & 10.65 & 11.17 & 12.25 & 14.14 \\
& $(.45)$ & $(.49)$ & $(.79)$ & $(.50)$ \\
\hline Ln head's age & 3.789 & 3.809 & 3.824 & 3.842 \\
& $(.33)$ & $(.32)$ & $(.32)$ & $(.32)$ \\
\hline Consumer units number & 2.500 & 2.471 & 2.432 & 2.415 \\
& $(.98)$ & $(.99)$ & $(.986)$ & $(.98)$ \\
\hline Ln family size & 1.140 & 1.121 & 1.095 & 1.081 \\
& $(.59)$ & $(.60)$ & $(.61)$ & $(.61)$ \\
\hline Number of Households & 3630 & 3630 & 3630 & 3630 \\
\hline
\end{tabular}

Table 2.2. Average budget shares.

\begin{tabular}{|c|c|c|c|c|}
\hline Budget shares & 1987 & 1988 & 1989 & 1990 \\
\hline Food & 0.432 & 0.400 & 0.435 & 0.483 \\
\hline Alcohol and tobacco & 0.041 & 0.037 & 0.031 & 0.129 \\
\hline Clothing & 0.129 & 0.141 & 0.145 & 0.096 \\
\hline Dwelling & 0.110 & 0.112 & 0.125 & 0.097 \\
\hline Energy & 0.033 & 0.039 & 0.022 & 0.039 \\
\hline Health and hygiene & 0.026 & 0.024 & 0.020 & 0.026 \\
\hline Transp. and communic. & 0.050 & 0.062 & 0.063 & 0.066 \\
\hline Culture and entertain. & 0.066 & 0.078 & 0.075 & 0.080 \\
\hline Other & 0.028 & 0.025 & 0.020 & 0.031 \\
\hline Financial operations & 0.087 & 0.081 & 0.057 & 0.050 \\
\hline
\end{tabular}


Table 2.3. Violation Probabilities According to Various Socio-economic Characteristics Logistic Function Regression.

\begin{tabular}{|c|c|c|}
\hline Budget shares & Parameter Estimates & Standard Error \\
\hline Intercept & -3.1525 & 0.2755 \\
\hline $\begin{array}{l}\text { \%Change in real per UC } \\
\text { total expenditure }(88-87)\end{array}$ & 0.2218 & 0.1959 \\
\hline $\begin{array}{l}\text { \% Change in real per UC } \\
\text { total expenditure }(89-88)\end{array}$ & 0.4830 & 0.2125 \\
\hline $\begin{array}{l}\text { \% Change in real per UC } \\
\text { total expenditure }(90-89)\end{array}$ & 0.8111 & 0.1843 \\
\hline Change in food budget coeff $(88-87)$ & 0.4726 & 0.7823 \\
\hline Change in food budget coeff (89-88) & 0.8673 & 0.6761 \\
\hline Change in food budget coeff (90-89) & 0.8082 & 0.6384 \\
\hline Change in family size $(88-87)$ & -0.1307 & 0.1316 \\
\hline Change in family size (89-88) & -0.2744 & 0.1631 \\
\hline Change in family size (90-89) & 0.2834 & 0.1103 \\
\hline \multicolumn{3}{|l|}{$\begin{array}{c}\text { Family head's age (less than 40) } \\
\text { (ref) }\end{array}$} \\
\hline Family head's age (41-60) & -0.0227 & 0.1705 \\
\hline Family head's age more than 60 & -0.1750 & 0.2693 \\
\hline \multicolumn{3}{|l|}{$\begin{array}{c}\text { Location (large city) } \\
\text { (ref) }\end{array}$} \\
\hline Location (average size city) & 0.3327 & 0.2370 \\
\hline Location (small town) & -0.2552 & 0.3553 \\
\hline Location (countryside) & 0.3124 & 0.2128 \\
\hline \multicolumn{3}{|l|}{$\begin{array}{c}\text { Education (college-university level) } \\
\text { (ref) }\end{array}$} \\
\hline Education (average level) & -0.1140 & 0.1643 \\
\hline Education (primary school level) & -0.0311 & 0.2934 \\
\hline \multicolumn{3}{|l|}{$\begin{array}{c}\text { Wage earners } \\
\text { (ref) }\end{array}$} \\
\hline Farmers & 0.0174 & 0.2269 \\
\hline Mixed: farmers and wage earners & -0.3551 & 0.2343 \\
\hline Retired People & 0.3624 & 0.2329 \\
\hline \multicolumn{3}{|l|}{$\begin{array}{l}\text { Survey's quarter (1) } \\
\text { (ref) }\end{array}$} \\
\hline Survey's quarter (2) & 0.1609 & 0.2052 \\
\hline Survey's quarter (3) & 0.4147 & 0.2022 \\
\hline Survey's quarter (4) & 0.3766 & 0.2121 \\
\hline
\end{tabular}

Model Fitting Information and Testing Global Null Hypothesis BETA=0

$\begin{array}{cccc} & \begin{array}{c}\text { Intercept } \\ \text { Only }\end{array} & \begin{array}{c}\text { Intercept and } \\ \text { Covariates }\end{array} & \begin{array}{c}\text { Chi square } \\ \text { for covariates }\end{array} \\ \text {-2LOGL } & 1767.618 & 1713.969 & 53.649 \text { with 22 DF }(\mathrm{p}=0.0002)\end{array}$


Table 2.4. Income Elasticities (QAIDS).

\begin{tabular}{|l|c|c|c|c|}
\hline \multirow{2}{*}{} & \multicolumn{3}{|c|}{$\begin{array}{c}\text { Cross-section } \\
\text { Elasticities }\end{array}$} \\
& \multicolumn{2}{c|}{$\begin{array}{c}\text { Eirst-difference } \\
\text { Elasticities }\end{array}$} \\
\cline { 2 - 5 } & $\mathrm{NV}$ & $\mathrm{V}$ & $\mathrm{NV}$ & $\mathrm{V}$ \\
\hline Food at home & 0.637 & 0.747 & 0.774 & 1.022 \\
& $(.015)$ & $(.054)$ & $(.018)$ & $(.064)$ \\
\hline Food away & 1.574 & 1.128 & 1.574 & -0.005 \\
& $(.211)$ & $(.564)$ & $(.253)$ & $(.744)$ \\
\hline Alcohol and tobacco & 1.115 & 0.778 & 0.976 & 0.580 \\
& $(.041)$ & $(.051)$ & $(.048)$ & $(.174)$ \\
\hline Dwelling & 1.311 & 1.495 & 1.316 & 1.427 \\
& $(.044)$ & $(.054)$ & $(.062)$ & $(.227)$ \\
\hline Energy & 0.358 & 0.185 & 0.805 & 0.583 \\
& $(.071)$ & $(.039)$ & $(.095)$ & $(.341)$ \\
\hline Clothing & 1.080 & 1.111 & 1.026 & 0.861 \\
& $(.031)$ & $(.107)$ & $(.041)$ & $(.148)$ \\
\hline Transport and & 1.676 & 1.715 & 1.261 & 1.144 \\
& $(.059)$ & $(.207)$ & $(.078)$ & $(.277)$ \\
Communication & & & & \\
\hline Health and Hygiene & 0.627 & 0.564 & 0.681 & 0.442 \\
& $(.043)$ & $(.049)$ & $(.057)$ & $(.197)$ \\
\hline Culture and Education & 1.529 & 1.280 & 1.327 & 0.921 \\
& $(.047)$ & $(.067)$ & $(.067)$ & $(.232)$ \\
\hline Other & 1.377 & 1.516 & 1.278 & 1.354 \\
& $(.071)$ & $(.213)$ & $(.103)$ & $(.288)$ \\
\hline Financial Operations & 1.834 & 1.398 & 1.399 & 0.790 \\
& $(.059)$ & $(.212)$ & $(.081)$ & $(.287)$ \\
\hline
\end{tabular}

Legend.

$\mathrm{NV}=$ Non-violating households, $\mathrm{V}=$ Violating households

Estimation: $w_{i h t}=\alpha_{i}+\sum_{j} \gamma_{i j} \ln p_{j t}+\beta_{i} \times \ln \frac{m_{h t}}{a\left(p_{t}\right)}+\left(\frac{\lambda_{i}}{b\left(p_{t}\right)} \times \frac{m_{h t}}{a\left(p_{t}\right)}\right)^{2}+w_{h t} \gamma_{i}+u_{i h t}$

with $\ln a\left(p_{t}\right)=\alpha_{0}+\sum_{i} \alpha_{i} \ln p_{i t}+0.5 \sum_{i} \sum_{j} \gamma_{i j} \ln p_{i t} \times \ln p_{j t}$ and $b\left(p_{t}\right)=\prod_{i} p_{i t}^{\beta_{i}}$

Logarithm of total Expenditures instrumented.

Other determinants: logarithmic age of the head of household, proportion of children in the family,

relative logarithmic prices, education and location dummies, and quarter dummies for each year. The true price index is approximated by a Stone price index.

Estimation: By convergence, third iteration for both dimensions on the integrability parameter

$b\left(p_{t}\right)$. Additivity and homogeneity constrained.

Dataset: Polish panel including 3630 households for period 1987.I-1990.IV. 
Table 2.5. Proportion of Social Classes in 1987, 1988, 1989 and 1990 (\%).

\begin{tabular}{|l|c|c|c|c|c|c|c|c|c|c|}
\hline & \multicolumn{2}{|c|}{ Poor } & \multicolumn{2}{c|}{$\begin{array}{c}\text { Quasi } \\
\text { Poor }\end{array}$} & \multicolumn{2}{c|}{$\begin{array}{c}\text { Middle } \\
\text { Class }\end{array}$} & \multicolumn{2}{c|}{$\begin{array}{c}\text { Quasi } \\
\text { Rich }\end{array}$} & \multicolumn{2}{c|}{ Rich } \\
\hline \hline $\mathbf{1 9 8 7}$ & $\mathrm{NV}$ & $\mathrm{V}$ & $\mathrm{NV}$ & $\mathrm{V}$ & $\mathrm{NV}$ & $\mathrm{V}$ & $\mathrm{NV}$ & $\mathrm{V}$ & $\mathrm{NV}$ & $\mathrm{V}$ \\
& & & & & & & & & & \\
\hline$k=0.25$ & $143(\mathrm{a})$ & 13 & 918 & 65 & 1282 & 89 & 916 & 63 & 131 & 10 \\
& $4.22 \%(b)$ & 5.42 & 27.08 & 27.08 & 37.82 & 37.08 & 27.02 & 26.25 & 3.86 & 4.17 \\
\hline$k=0.15$ & 223 & 21 & 701 & 48 & 1592 & 109 & 675 & 47 & 199 & 15 \\
& $6.58 \%$ & 8.75 & 20.68 & 20.00 & 46.9 & 45.10 & 19.91 & 19.58 & 5.87 & 6.25 \\
\hline$k=0.10$ & 266 & 26 & 563 & 38 & 1770 & 123 & 556 & 35 & 235 & 18 \\
& $7.85 \%$ & 10.83 & 16.61 & 15.83 & 52.21 & 16.40 & 51.25 & 14.58 & 6.93 & 7.50 \\
\hline \hline $\mathbf{1 9 8 8}$ & $\mathrm{NV}$ & $\mathrm{V}$ & $\mathrm{NV}$ & $\mathrm{V}$ & $\mathrm{NV}$ & $\mathrm{V}$ & $\mathrm{NV}$ & $\mathrm{V}$ & $\mathrm{NV}$ & $\mathrm{V}$ \\
& & & & & & & & & & \\
\hline$k=0.10$ & $8.2 \%$ & 7.5 & 16.8 & 18.3 & 51.6 & 50.4 & 15.6 & 12.9 & 7.7 & 10.8 \\
\hline$k=0.25$ & $4.2 \%$ & 3.8 & 27.1 & 27.1 & 38.5 & 37.9 & 25.5 & 25.4 & 4.7 & 5.8 \\
\hline \hline $\mathbf{1 9 8 9}$ & $\mathrm{NV}$ & $\mathrm{V}$ & $\mathrm{NV}$ & $\mathrm{V}$ & $\mathrm{NV}$ & $\mathrm{V}$ & $\mathrm{NV}$ & $\mathrm{V}$ & $\mathrm{NV}$ & $\mathrm{V}$ \\
& & & & & & & & & & \\
\hline$k=0.10$ & $8.9 \%$ & 10.4 & 16.3 & 15.8 & 48.4 & 53.3 & 16.3 & 12.1 & 10.1 & 8.3 \\
\hline$k=0.25$ & $5.10 \%$ & 4.17 & 26.0 & 29.8 & 36.3 & 39.2 & 25.2 & 20.8 & 7.4 & 6.3 \\
\hline \hline $\mathbf{1 9 9 0}$ & $\mathrm{NV}$ & $\mathrm{V}$ & $\mathrm{NV}$ & $\mathrm{V}$ & $\mathrm{NV}$ & $\mathrm{V}$ & $\mathrm{NV}$ & $\mathrm{V}$ & $\mathrm{NV}$ & $\mathrm{V}$ \\
& & & & & & & & & & \\
\hline$k=0.10$ & $5.84 \%$ & 5.92 & 17.0 & 15.4 & 51.9 & 53.3 & 16.2 & 15.00 & 9.0 & 10 \\
\hline$k=0.25$ & $2.42 \%$ & 1.25 & 27.6 & 26.7 & 37.2 & 39.2 & 27.7 & 25.8 & 5.0 & 7.9 \\
\hline
\end{tabular}

Legend.

$\mathrm{NV}=$ Non-violating households, $\mathrm{V}=$ Violating households Poverty criteria:

(i) Income per unit of consumption below the first quintile.

(ii) Total expenditure per unit of consumption smaller than $(1-k)$ time the average for a reference population.

(iii) Budget share for food at home greater than $(1+k)$ the average for a reference population. Definition of social classes:

The rich are defined symmetrically, the quasi-poor (respectively the quasi-rich) as having two over the three attributes of the poor (respectively the rich) and not being rich (respectively the poor) for the third.

Frequency (a) and Percentage (b) of violating (V) or non-violating (NV) households.

Table 2.6. Social Class Changes: Proportion of households changing to other social classes between two years.

\begin{tabular}{|l|c|c|c|c|c|c|c|c|}
\hline \multirow{2}{*}{} & \multicolumn{2}{|c|}{$\mathbf{1 9 8 7 / 8 8}$} & \multicolumn{2}{c|}{$\mathbf{1 9 8 8} / \mathbf{8 9}$} & \multicolumn{2}{c|}{$\mathbf{1 9 8 9} / \mathbf{9 0}$} & \multicolumn{2}{c|}{ Average } \\
\cline { 2 - 9 } & $\mathrm{NV}$ & $\mathrm{V}$ & $\mathrm{NV}$ & $\mathrm{V}$ & $\mathrm{NV}$ & $\mathrm{V}$ & $\mathrm{NV}$ & $\mathrm{V}$ \\
\hline$k=0.1 ; n c=1$ & 0.460 & 0.429 & 0.592 & 0.554 & 0.524 & 0.517 & 0.525 & 0.500 \\
\hline$k=0.1 ; n c>1$ & 0.079 & 0.092 & 0.168 & 0.163 & 0.112 & 0.100 & 0.120 & 0.118 \\
\hline$k=0.25 ; n c>1$ & 0.038 & 0.042 & 0.145 & 0.133 & 0.077 & 0.088 & 0.087 & 0.088 \\
\hline
\end{tabular}

Legend.

$\mathrm{NV}=$ Non-violating households, $\mathrm{V}=$ Violating households

$k$ is the parameter defined in Table 2.5.

$n c$ is the number of social class change. 


\section{Appendix III}

Table 3.1. Absolute Changes in Logarithmic Shadow Prices: $I_{a}\left(\pi^{v}\right)$.

\begin{tabular}{|l|c|c|c|c|c|c|c|c|c|c|c|c|}
\hline \multirow{2}{*}{} & \multicolumn{2}{|c|}{ TP1 } & \multicolumn{2}{c|}{ TP2 } & \multicolumn{2}{c|}{ DP } & \multicolumn{2}{c|}{ TP1' } & \multicolumn{2}{c|}{ TP2' } & \multicolumn{2}{c|}{ DP' } \\
\cline { 2 - 14 } Period & NV & V & NV & V & NV & V & NV & V & NV & V & NV & V \\
\hline $87-88$ & 0.193 & 0.154 & 0.286 & 0.315 & 0.188 & 0.258 & 0.135 & 0.108 & 0.108 & 0.141 & 0.130 & 0.186 \\
\hline $88-89$ & 0.214 & 0.173 & 0.119 & 0.351 & 0.208 & 0.287 & 0.148 & 0.122 & 0.118 & 0.157 & 0.142 & 0.210 \\
\hline $89-90$ & 0.282 & 0.217 & 0.131 & 0.441 & 0.274 & 0.358 & 0.197 & 0.152 & 0.157 & 0.196 & 0.188 & 0.262 \\
\hline
\end{tabular}

\section{Legend.}

$I_{a}\left(\pi^{v}\right)=\frac{1}{H} \times \sum_{h}\left[\frac{1}{T-1} \sum_{t} \sum_{i} w_{i} \cdot\left|d \ln \pi_{i h t}\right|\right]$

$\mathrm{NV}=$ Non-violating households, $\mathrm{V}=$ Violating households

$\mathrm{TP} 1=$ Total population, budget share equalized: price marginal propensity $=\beta_{i i}$

$\mathrm{TP} 1{ }^{\prime}=$ Total population, expenditure equalized: price marginal propensity $=\beta_{i i}-w_{i}$

TP2 $=$ Total population, budget share equalized and differenced income and squared income coef-

ficients.

TP2' = Total population, expenditure equalized and differenced income and squared income coef-

ficients.

$\mathrm{DP}=$ Different populations (violating versus non-violating), budget share equalized

$\mathrm{DP}^{\prime}=$ Different populations (violating versus non-violating), expenditure equalized.

Table 3.2. Indexes of changes in logarithmic shadow prices.

\begin{tabular}{|c|c|c|c|c|c|c|c|c|c|c|}
\hline & \multicolumn{4}{|c|}{$\begin{array}{c}\text { Index for } \\
\text { all expenditures }\end{array}$} & \multicolumn{2}{|c|}{$\begin{array}{c}\text { Index for } \\
\text { food at home }\end{array}$} & \multicolumn{2}{|c|}{$\begin{array}{l}\text { Index for } \\
\text { clothing }\end{array}$} & \multicolumn{2}{|c|}{$\begin{array}{l}\text { Index for } \\
\text { housing }\end{array}$} \\
\hline & NV & NV & $\bar{V}$ & $\bar{V}$ & $\mathrm{NV}$ & $\overline{\mathrm{V}}$ & NV & $\overline{\mathrm{V}}$ & NV & $\bar{V}$ \\
\hline & $I_{q}\left(\pi^{v}\right)$ & $I_{a}\left(\pi^{v}\right)$ & $I_{q}\left(\pi^{v}\right)$ & $I_{a}\left(\pi^{v}\right)$ & $I_{q}\left(\pi^{v}\right)$ & $I_{q}\left(\pi^{v}\right)$ & $I_{q}\left(\pi^{v}\right)$ & $I_{q}\left(\pi^{v}\right)$ & $I_{q}\left(\pi^{v}\right)$ & $I_{q}\left(\pi^{v}\right)$ \\
\hline $1987-88$ & $\begin{array}{l}0.236 \\
(.009)\end{array}$ & 0.286 & $\begin{array}{l}0.812 \\
(.017)\end{array}$ & 0.315 & $\begin{array}{c}0.007 \\
(.0005)\end{array}$ & $\begin{array}{c}0.039 \\
(.0026)\end{array}$ & $\begin{array}{c}0.007 \\
(.0002)\end{array}$ & $\begin{array}{c}0.034 \\
(.0014)\end{array}$ & $\begin{array}{c}0.002 \\
(.0001)\end{array}$ & $\begin{array}{c}0.002 \\
(.0003)\end{array}$ \\
\hline $1988-89$ & $\begin{array}{l}0.0265 \\
(.006)\end{array}$ & 0.119 & $\begin{array}{l}0.902 \\
(.012)\end{array}$ & 0.351 & $\begin{array}{l}0.008 \\
(.0005)\end{array}$ & $\begin{array}{l}0.050 \\
(.0035)\end{array}$ & $\begin{array}{l}0.005 \\
(.0002)\end{array}$ & $\begin{array}{c}0.047 \\
(.0022)\end{array}$ & $\begin{array}{l}0.003 \\
(.0001)\end{array}$ & $\begin{array}{c}0.002 \\
(.0003)\end{array}$ \\
\hline $1989-90$ & $\begin{array}{l}1.287 \\
(.003)\end{array}$ & 0.131 & $\begin{array}{l}1.137 \\
(.009)\end{array}$ & 0.441 & $\begin{array}{l}0.129 \\
(.015)\end{array}$ & $\begin{array}{l}0.073 \\
(.006)\end{array}$ & $\begin{array}{c}0.007 \\
(.0021)\end{array}$ & $\begin{array}{l}0.069 \\
(.0037)\end{array}$ & $\begin{array}{c}0.034 \\
(.0017)\end{array}$ & $\begin{array}{l}0.003 \\
(.0004)\end{array}$ \\
\hline
\end{tabular}

Legend.

$\mathrm{NV}=$ Non-violating households, $\mathrm{V}=$ Violating households

Estimation: Separately on pooled cross section and first differences. The variance of the difference

of the two estimators is taken as the sum of the variances of each estimator. Estimation TP2.

Quadratic index: $I_{q}\left(\pi^{v}\right)=\sqrt{\frac{1}{H} \times \sum_{h}\left[\frac{1}{T-1} \sum_{t} \sum_{i} w_{i} .\left(\operatorname{dln} \pi_{i h t}\right)^{2}\right]}$

Absolute index: $I_{a}\left(\pi^{v}\right)=\frac{1}{H} \times \sum_{h}\left[\frac{1}{T-1} \sum_{t} \sum_{i} w_{i} \cdot\left|d l n \pi_{i h t}\right|\right]$

Index variances: see Appendix IV. 


\section{Appendix IV}

\section{D.1 Revelation of the shadow prices.}

Two problems arise in the computation of shadow prices:

First, the shadow prices are computed in section 5.2 by equalizing the estimated budget share by cross-section plus the shadow price effect and the estimated budget share on time series. This method assumes that the constant term is the same in the two estimations. Thus, the levels of the revealed shadow prices are disputable. However, the variation of the shadow prices between two periods, say $d l p_{v i t}=\sum_{i} \frac{d \pi_{i}}{d Z_{1 h}} \cdot d Z 1 h t$ with $\frac{d \pi_{i}}{d Z_{1 h}}=\frac{\beta_{i}^{(c . s .)}-\beta_{i}^{(t . s .)}}{\gamma_{i i}}$, is more reliable.

Second, it is also possible to reveal the variation of the shadow prices by equalizing the expenditures instead of the budget shares. Let us consider a logarithmic equation:

$$
\log C_{i}=Z . \beta_{i}^{(c . s .)}+u_{i}^{(c . s .)}=Z . \beta_{i}^{(t . s .)}+E_{i}^{p} \log \pi_{i}+u_{i}^{(t . s .)}
$$

with $E_{i}^{p}$ the direct price-elasticity and $C_{i}$ the consumption of good $i$. By separating the parameters of income from other determinants, we get

$$
\frac{d \log \pi_{i}}{d Z_{1 h}}=\frac{\beta_{i}^{(\text {c.s. })}-\beta_{i}^{(t . s .)}}{\gamma_{i i}-w_{i}}
$$

, with $w_{i}$ as the average budget share for commodity $i$ (this is easily proved by equalizing the income elasticities of this logarithmic specification with the elasticity computed by an AI specification).

Thus, to reveal the shadow prices, the two above hypotheses amount to dividing the difference between cross-section and time series estimators, either by $\gamma_{i i}$, or by $\left(\gamma_{i i}-w_{i}\right)$.

\section{D.2 Estimation for the two sub-populations.}

Let us estimate the following model $y=x \beta+u$ over two sub-populations of sizes $n$ and $n^{\prime}$ with $n<n^{\prime}$. Let $\hat{\beta}$ be the estimator of the vector of parameters for the sub-population of size $n$, and Let $\hat{\beta}^{\prime}$ be the estimator of the vector of parameters for the sub-population of size $n^{\prime}$.

These estimators can be written $\hat{\beta}=\beta+t \sigma$ and $\hat{\beta}^{\prime}=\beta^{\prime}+t^{\prime} \sigma$ with $\beta$ and $\beta^{\prime}$ as the true parameters and $\sigma$ the standard error of the parameters which is supposed to be the same for the two parameters.

We suppose also that:

- $\hat{\beta}$ and $\hat{\beta}^{\prime}$ are independent.

- The expected mean of $t=$ the expected mean of $t^{\prime}=0$.

- The standard error of $t=$ the standard error of $t^{\prime}=s$. 
- $\frac{\partial s}{\partial N}<0$, where $N$ is the population's size.

This implies: $\hat{\beta}-\hat{\beta}^{\prime}=\left(\beta-\beta^{\prime}\right)+\left(t-t^{\prime}\right) \sigma$ and $\operatorname{Var}\left(\hat{\beta}-\hat{\beta}^{\prime}\right)=2 s^{2} \sigma^{2}$.

The difference between the estimators on the two populations is not biased with respect to 0 , but it decreases with the size of the sub-populations.

Therefore, the difference between cross-sections and time-series estimators, which is a component of the shadow prices' formulas, is probably greater for the smaller population and that may artificially increase the variation of the shadow prices. Hence the shadow prices computed over the violating households are over-estimated compared to those computed through a regression over the nonviolating households (remember that the non-violating households are about ten times more numerous than the violating households).

On the other hand, estimating the difference $\beta^{(\text {c.s. })}-\beta^{(\text {t.s. })}$ on the whole population and using this difference to compute the shadow prices for the two populations (violating/non-violating) can be considered misspecified. Indeed, we have proved that the consumption behavior differs between the two populations at least for the income parameters (Table 2.4). Since the income and squared income coefficients are well estimated for both populations, the method that we prefer for computing the shadow prices consists in estimating $\beta^{(c . s .)}$ and $\beta^{(t . s .)}$ on the whole population with dummies indicating the violating and non-violating for the income coefficients (column TP2 in Table 3.1, Appendix III). 


\section{E Appendix V: Distribution of the Quadratic In- dex of Shadow Prices}

\section{E.1 Computation of the variances:}

The quadratic index writes: $I_{q}\left(\pi^{v}\right)=\sqrt{\frac{1}{H} \cdot \sum_{h}\left(\frac{1}{T-1} \sum_{t} \sum_{i} w_{i} \cdot\left(d l n \pi_{i h t}\right)^{2}\right)}$.

(i) The logarithmic virtual prices $d l n \pi_{i h t}$ are normally distributed as linear transformations of the differences between cross-sections and time-series parameters (which are, by assumption, normal). The variance of $d l n \pi_{i h t}$ is :

$$
\operatorname{Var}\left(d \ln \pi_{i h t}\right)=\left(d Z_{1 h t}\right) \operatorname{Var}\left[\beta_{B}-\beta_{W}\right]\left(d Z_{1 h t}\right)^{\prime}
$$

with $\operatorname{Var}\left[\beta_{B}-\beta_{W}\right]=\operatorname{Var}\left(\beta_{B}\right)+\operatorname{Var}\left(\beta_{W}\right):$ see BALTAGI [1995, p.69].

(ii) The variance of $\left(d \ln \pi_{i h t}\right)^{2}$ can be computed using the formula characterizing normal variables (here $\left.d l n \pi_{i h t}\right)$ :

$$
\operatorname{Var}\left[\left(d l n \pi_{i h t}\right)^{2}\right]=2 \sigma_{i}^{4}+4 m_{i}^{2} \sigma_{i}^{2}
$$

with $m_{i}$ and $\sigma_{i}$ respectively the mean and standard-error of $d l n \pi_{i}$. Thus, under an independence assumption, the variance of the square of the quadratic index $I_{q}$ is the weighed average of these variances:

$$
\operatorname{Var}\left[\sum_{i} w_{i}\left(\operatorname{dln} \pi_{i n t}\right)^{2}\right]=\sum_{i} w_{i}^{2}\left[2 \sigma_{i}^{4}+4 m_{i}^{2} \sigma_{i}^{2}\right]
$$

(iii) Finally, we assume (hypothesis 1.iii) that $I_{q}$ is normal, so that the formula (E.1) applies also to this index and its square:

$$
\operatorname{Var}\left(I_{q}^{2}\right)=2\left(\operatorname{Var}\left(I_{q}\right)\right)^{2}+4\left(E\left(I_{q}\right)\right)^{2} . \operatorname{Var}\left(I_{q}\right)
$$

The positive solution for this equation writes:

$$
\operatorname{Var}\left(I_{q}\right)=-I_{q}^{2}+\sqrt{I_{q}^{4}+0.5 \operatorname{Var}\left(I_{q}^{2}\right)}
$$

The different elements of this formula are taken as the average of $I_{q}^{2}$ and its variance over each sub-population composed respectively of the violating and non-violating households.

\section{E.2 Distribution of the quadratic index $I_{q}$ :}

As a weighted average of non-centered heteroskedastic normal variables, $I_{q}$ has no known distribution (let us point out however that in mathematical-statistics there are - in very special cases unfortunately - some non-centered limit theorems). The Jarque-Bera statistic amounts to 181.58 and is higher than the limit of a $\chi^{2}(2 d f)$. As a consequence, the distribution of $I_{q}$ does not seem to be a normal distribution.

Nevertheless, we keep our assumption that $I_{q}$ follows a normal distribution because a Monte Carlo experiment for 300 households and 80 draws shows that its histogram is close to the one of a normal distribution (see appendix E.3). Therefore, we use the computed variances to test whether the quadratic index is significantly different from zero and greater for the violating households. 


\section{E.3 Histogram of $I_{q}$}

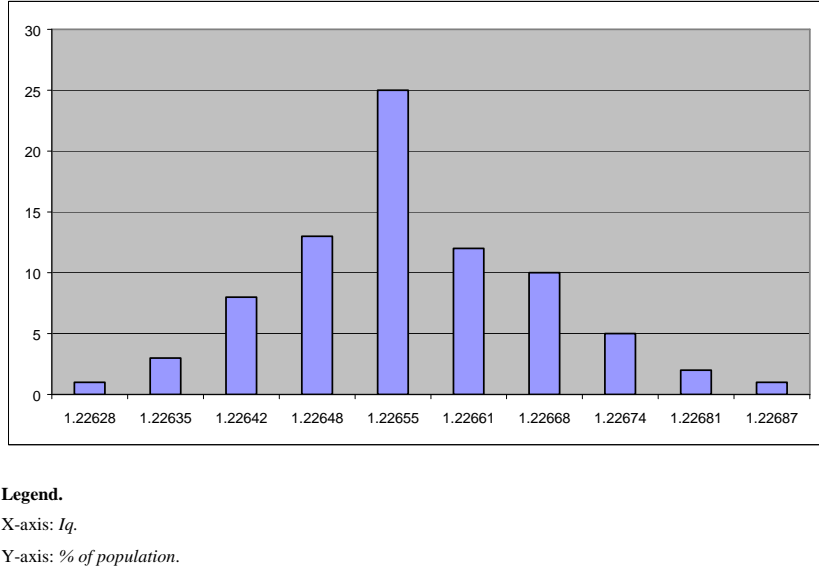

